\title{
Reatores híbridos anaeróbio e aeróbio para remoção de matéria orgânica e nitrogênio em esgoto doméstico diluído
}

\author{
Hybrid anaerobic and aerobic reactors for organic \\ matter and nitrogen removal in diluted domestic sewage
}

\begin{abstract}
Marcus Vinícius Alves dos Santos ${ }^{1} \oplus$, Juliana Cardoso de Morais ${ }^{1,2} \odot$, Shyrlane Torres Soares Veras ${ }^{1} \oplus$, Wanderli Rogério Moreira Leite ${ }^{1} \oplus$, Savia Gavazza' $\odot$, Lourdinha Florencio' $₫$, Mario Takayuki Kato ${ }^{1 *} \odot$
\end{abstract}

\section{RESUMO}

A remoção de matéria orgânica e de nitrogênio em esgoto doméstico diluído foi avaliada em dois reatores híbridos, um anaeróbio (RHAN) e outro aeróbio (RHAE). O RHAN era formado por uma câmara tipo upflow anaerobic sludge blanket sobreposta por outra de filtro anaeróbio, enquanto o RHAE tinha uma câmara de lodo ativado sobreposta por outra de biofilme aerado submerso. A operação do sistema foi dividida em duas fases, Fl e Fll, com razões de recirculação de 50 e 75\% e duração de 94 e 110 dias, respectivamente. Para a remoção de nitrogênio, o RHAE foi operado com oxigênio dissolvido de 3,0 mg.L¹. A técnica da reação em cadeia da polimerase foi empregada tanto para o lodo suspenso das câmaras inferiores, como para o biofilme aderido nas câmaras superiores, para identificar a presença de micro-organismos desnitrificantes e nitrificantes. As maiores eficiências de remoção em termos de demanda química de oxigênio e nitrogênio total foram obtidas em Fll, sendo 91\% e $50 \%$, respectivamente; as concentrações no efluente foram

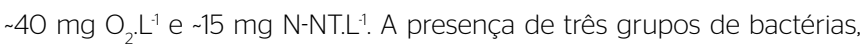
as desnitrificantes, as oxidantes de amônia e as oxidantes de nitrito, foi confirmada no biofilme aderido do RHAE, indicando uma biomassa mixotrófica e sugerindo a possibilidade do processo de nitrificação e desnitrificação simultânea.

Palavras-chave: UASB; filtro anaeróbio; lodos ativados; biofiltro aerado submerso; nitrificação e desnitrificação; esgoto diluído.

\begin{abstract}
The removal of organic matter and nitrogen in diluted domestic sewage was evaluated in two hybrid reactors, one anaerobic (ANHR) and another aerobic (AEHR). ANHR was formed by a upflow anaerobic sludge blanket (UASB)-type chamber overlaid by an anaerobic filter, while AEHR had an activated sludge chamber overlaid by a submerged aerated biofilm chamber. The experimental period was divided into two phases, FI and FII, with recirculation ratios of 50 and $75 \%$, and duration of 94 and 110 days, respectively. For nitrogen removal, AEHR was operated with a 3.0-mg. L $^{-1}$ dissolved oxygen. Polymerase chain reaction technique was used for both suspended sludge in the down-chambers and attached biofilm in the upper-chambers, to identify the presence of denitrifying and nitrifying microorganisms. The highest removal efficiencies in terms of chemical oxygen demand and total nitrogen were obtained in FIl, being 91 and $50 \%$, respectively; effluent concentrations were $\sim 40 \mathrm{mg}$ $\mathrm{O}_{2} \cdot \mathrm{L}^{-1}$ and $\sim 15 \mathrm{mg} \mathrm{N}-\mathrm{TN} . \mathrm{L}^{-1}$. The presence of three groups of bacteria, the denitrifiers, the ammonia oxidants and the nitrite oxidants, was confirmed in the attached biofilm of the RHAE, indicating a mixotrophic biomass and suggesting the possibility of simultaneous nitrification and denitrification process.
\end{abstract}

Keywords: UASB; anaerobic filter; activated sludge; submerged aerated biofilm; nitrification and denitrification; diluted domestic sewage. 


\section{INTRODUÇÃO}

Em regiões tropicais e subtropicais, os processos anaeróbios para o tratamento de esgotos domésticos se encontram bem consolidados, em especial com o emprego de reatores do tipo upflow anaerobic sludge blanket (UASB). Tem sido obtida relativamente elevada eficiência de remoção de matéria orgânica (LETTINGA et al., 1993; BARROS et al., 2015; WALIA; KUMAR; MEHROTRA, 2020), mas como ocorre em sistemas biológicos anaeróbios ou aeróbios convencionais, a remoção de nutrientes, como nitrogênio e fósforo, é baixa (PATHAK et al., 2020). Frações remanescentes de matéria orgânica, nitrogênio e fósforo causam impactos negativos ao meio ambiente, como é o caso de eutrofização em corpos aquáticos (PITTMAN; DEAN; OSUNDEKO, 2011; HU; REN, 2019). Para melhorar a eficiência do tratamento de esgotos e atender às regulamentações mais rigorosas, têm sido propostos sistemas alternativos de pós-tratamento (PANTOJA FILHO et al., 2015; ALLEGUE et al., 2020).

No caso de remoção de matéria orgânica e nitrogênio, têm sido aplicados sistemas combinando reatores híbridos contendo compartimentos com lodo suspenso na parte inferior e lodo aderido na parte superior; os reatores híbridos em sequência anaeróbia e aeróbia, com recirculação, favorecem a nitrificação e desnitrificação (LEYVA-DÍAZ et al., 2016; HOSSEINPOUR et al., 2019). Na parte inferior dos reatores, o lodo suspenso favorece a remoção de matéria orgânica e a desnitrificação, e a nitrificação, nos compartimentos anaeróbio e aeróbio, respectivamente; e as condições hidrodinâmicas otimizam o contato entre os substratos e os micro-organismos. Na parte superior, o meio suporte com lodo aderido favorece maior retenção de micro-organismos e, eventualmente, de biomassa carreada dos compartimentos inferiores, em especial das nitrificantes e desnitrificantes em suspensão, sujeitas frequentemente à perda por ocorrência de lavagem. Há, portanto, vantagens operacionais e econômicas com o uso de configuração convencional de reatores anaeróbio e aeróbio sequenciais, mas cada qual com compartimentos de lodo suspenso e lodo aderido separados, em função do menor volume, da área ocupada em planta e do menor requisito de bombeamento (LEYVA-DÍAZ et al., 2016; GONZALEZ-TINEO et al., 2020).

Leyva-Díaz et al. (2016) utilizaram um reator híbrido com lodo suspenso, razão de recirculação (RR) aplicada de 100 e 200\% e tempo de detenção hidráulica (TDH) de 18 horas. Eles obtiveram eficiência de remoção de demanda química de oxigênio (DQO) próxima a 83 e $86 \%$, respectivamente, com concentrações finais de 32 e 26 de $\mathrm{mg} \mathrm{O}_{2} \cdot \mathrm{L}^{-1}$, e para o nitrogênio, 59 e $58 \%$, respectivamente, com concentrações finais de 35 e $33 \mathrm{mg} \mathrm{N}-\mathrm{NT} . \mathrm{L}^{-1}$, respectivamente. Oliveira Netto e Zaiat (2012), operando reatores híbridos com TDH de 12 horas e RR de 50 e 150\%, reportaram eficiências de remoção de DQO de 92 e 95\%, com concentrações finais de 44 e $31 \mathrm{mg} \mathrm{O} \mathrm{O}_{2} \mathrm{~L}^{-1}$, respectivamente; e cerca de 65 e 75\% para nitrogênio, atingindo concentrações finais de 14 e $10 \mathrm{mg} \mathrm{N}-\mathrm{NT} . \mathrm{L}^{-1}$, respectivamente.

Adicionalmente à remoção convencional de matéria orgânica e nitrogênio em reatores híbridos separados com recirculação, é possível promover o processo conhecido como nitrificação e desnitrificação simultânea (NDS), obtendo melhores eficiências de remoção (MÜNCH; LANT; KELLER, 1996; PATHAK et al., 2020). Uma das condições seria operar o reator aeróbio com baixo teor de oxigênio dissolvido (OD), entre 1,0 e 3,0 mg. $\mathrm{L}^{-1}$. O processo NDS é considerado vantajoso, quando comparado aos processos convencionais, porque não necessita de um tanque anóxico adicional em um sistema contínuo, uma vez que a desnitrificação é proeminente também no reator aeróbio, junto com a nitrificação; e condições de operação mais estáveis podem ser mantidas sem precisar de uma combinação complexa entre um tanque aerado e outro anóxico (MÜNCH; LANT; KELLER, 1996; XIA et al., 2019).

A combinação de micro-organismos suspensos e aderidos em um mesmo reator pode proporcionar maior diversidade e concentração de biomassa no sistema. Uma biomassa mixotrófica, autotrófica e heterotrófica pode ser fundamental para a ocorrência e estabilidade de processo tipo NDS (FENG et al., 2018). Por exemplo, mesmo em condições anaeróbias, o gênero Nitrosomonas também pode oxidar amônia (SCHMIDT; BOCK, 1997; STEIN, 2019); e outros autores, como Park et al. (2006), sugeriram que arqueias também podem oxidar amônia a nitrito ou nitrato. Portanto, o processo NDS pode ser favorecido inclusive em um reator anaeróbio. Além disso, o processo de oxidação anaeróbia da amônia (anammox) pode acontecer tanto no reator anaeróbio, pela recirculação do efluente do reator aeróbio contendo nitrito (preferencialmente) ou nitrato, como também no próprio reator aeróbio com baixa aeração (FUCHS et al., 2017). Nesse processo, a amônia é parcialmente convertida em nitrito pelas bactérias oxidantes de amônia (BOA) e, posteriormente, as bactérias anammox convertem a amônia restante e o nitrito produzido em gás $\mathrm{N}_{2}$. De acordo com a literatura, as condições favoráveis para a ocorrência do processo anammox são: temperatura próxima a $35^{\circ} \mathrm{C}, \mathrm{pH}$ entre 6,7 e 8,3 , relação $\mathrm{DQO} / \mathrm{N}$ entre 0,2 e 2,5, OD de 0,2 mg. $\mathrm{L}^{-1}$ e tempo de retenção de sólidos (TRS) entre 2 a 30 dias (AHN, 2006; MIAO et al., 2018; DU et al., 2019).

O objetivo deste estudo foi avaliar a remoção de matéria orgânica carbonácea e nitrogênio em esgoto doméstico diluído, usando um sistema com dois reatores híbridos sequenciais anaeróbio-aeróbio em escala piloto, cada qual compartimentado com lodo suspenso e aderido. A presença de bactérias nitrificantes e desnitrificantes também foi avaliada por meio de técnicas de biologia molecular.

\section{METODOLOGIA}

\section{Descrição e operação do sistema de tratamento}

O sistema de tratamento era composto por dois reatores híbridos, cada qual com compartimentos ou câmaras de lodo suspenso e de lodo aderido. O primeiro reator híbrido era anaeróbio (RHAN), formado por uma câmara do tipo UASB e sobreposta por outra de filtro anaeróbio (FAN). Já o segundo era aeróbio (RHAE), composto por uma câmara de lodos ativados (LA) sobreposta por outra com biofilme aerado submerso (BAS). Os dois reatores híbridos foram confeccionados em fibra de vidro e as câmaras sobrepostas, instaladas como apresentado na Figura 1. Anéis de conduíte de PVC $(25 \times 25 \mathrm{~mm})$ foram utilizados como meio de suporte em leito com altura de $40 \mathrm{~cm}$ e instalado a 30 $\mathrm{cm}$ da base do FAN e do BAS. O sistema foi instalado e operado na estação de tratamento de esgotos domésticos (ETE) Mangueira, localizada na cidade de Recife, PE, que atendia aproximadamente 18.000 habitantes (população de projeto), recebendo esgoto bruto, classificado como diluído (KATO; FLORENCIO; ARANTES, 2003).

Os reatores híbridos utilizados neste estudo já vinham sendo operados em trabalhos de pesquisas anteriores. A partida foi, portanto, uma continuidade da sua operação. Já havia, no início do período experimental, biomassa ativa, cuja concentração era de 15,6 g SSV.L ${ }^{-1}$ no compartimento UASB do RHAN e de 1,4 g SSV.L ${ }^{-1}$ no reator LA do RHAE. A determinação dos sólidos (sólidos suspensos totais [SST] e sólidos suspensos voláteis [SSV]) foi realizada a cada 15 dias 
para as duas fases experimentais, coletando-se amostras de lodo nos registros ao longo dos reatores (Figura 1). Com o perfil de sólidos, determinava-se a sua concentração média. Ao final das fases FI e FII, a concentração no UASB subiu para 18,6 e 20,6 g SSV.L ${ }^{-1}$, respectivamente. Os valores no LA se mantiveram próximos aos da partida.

A alimentação do sistema de reatores híbridos foi feita de forma contínua, em fluxo ascendente e com vazão de 57 L.h ${ }^{-1}$, resultando em TDH total de 16 horas, sendo 8 horas em cada reator híbrido. A vazão de ar aplicada no RHAE (LA+BAS) foi de 25 L.min ${ }^{-1}$, com aeração por ar difuso utilizando compressor com pistão de ar (Schulz, modelo Patric Air). O deslocamento teórico foi de 283 L.min ${ }^{-1}$ para manter concentração média de OD de 3,0 $\pm 0,1 \mathrm{mg} \cdot \mathrm{L}^{-1}$. Esse valor foi monitorado no primeiro ponto localizado na base do LA (Figura 1). Parte do efluente final do sistema (efluente do BAS) foi recirculada para o RHAN (afluente do UASB), no intuito de promover a desnitrificação. A operação do sistema durou 204 dias e foi dividida em duas fases (F) diferenciadas pelas $R R$ aplicadas: 50\% (FI) e 75\% (FII) (Tabela 1). As cargas orgânicas e nitrogenadas diárias aplicadas foram determinadas no afluente das câmaras de cada reator do sistema e as remanescentes, no efluente final do sistema. Balanços de massa de matéria orgânica e nitrogênio foram efetuados para as diferentes condições operacionais nas fases FI e FII.

\section{Monitoramento físico-químico do sistema de tratamento}

Para as análises físico-químicas das amostras líquidas, além daquela do esgoto bruto afluente (P1af, Figura 1), foram coletadas as do efluente das quatro câmaras do sistema híbrido (pontos P2, P3, P4 e P5, respectivamente). Para controle da idade do lodo, não houve descarte intencional de lodo de excesso em ambos os reatores. A idade de lodo foi calculada com base na perda de sólidos com o efluente do UASB e do LA, como sendo a concentração de SSV no último registro, obtida na determinação do perfil de sólidos a cada 15 dias, quando se calculava também a massa existente dentro de cada reator. Os valores ao longo das fases variaram entre 30 e 36 dias para o UASB e entre 5 e 6 dias para o LA.

As amostras líquidas foram coletadas duas vezes por semana, para as determinações analíticas, seguindo-se os procedimentos do Standard Methods (APHA; AWWA; WPCF, 2012): DQO; nitrogênio total Kjeldahl (N-NTK); nitrogênio

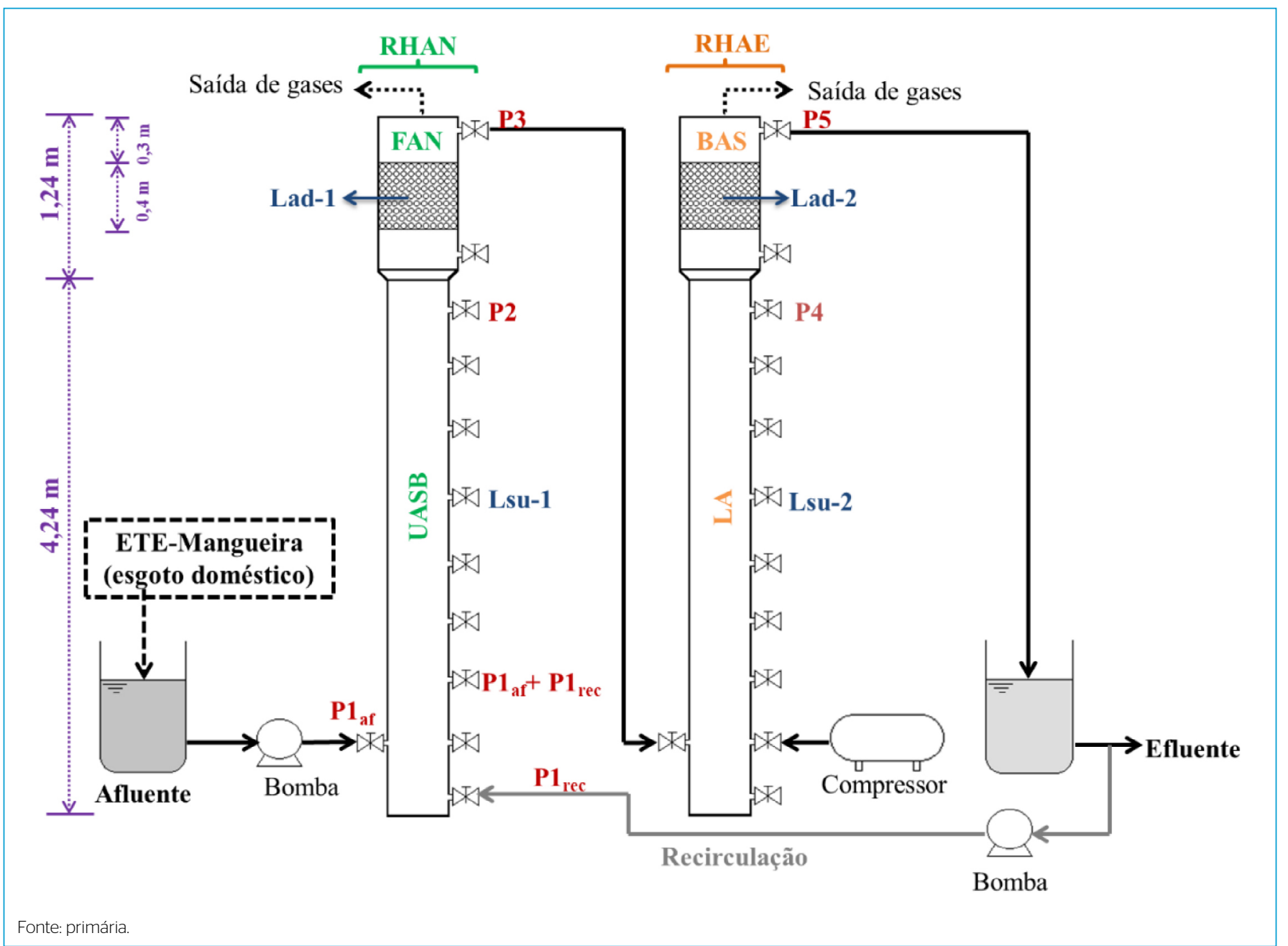

Figura 1 - Representação esquemática dos reatores híbridos anaeróbio (RHAN: UASB + FAN) e aeróbio (RHAE: LA + BAS). Dimensões das câmaras UASB e LA (altura × diâmetro): 4,24 × 0,30 m (volume $300 \mathrm{~L}$ ); FAN e BAS: 1,24 × 0,40 m (volume $156 \mathrm{~L}$ ). Os pontos de amostragem para o afluente, recirculação, mistura entre o afluente e o efluente recirculado, efluente do UASB, efluente do FAN, efluente do LA e efluente do BAS estão representados por $\mathrm{P1}_{\mathrm{aP}} \mathrm{P1}_{\text {rec }}, \mathrm{P}_{\text {af }}+\mathrm{P} 1_{\text {rec }}, \mathrm{P} 2, \mathrm{P} 3, \mathrm{P} 4$ e $\mathrm{P} 5$, respectivamente. Os pontos de coleta de biomassa suspensa e aderida para análises de biologia molecular estão representados por Lsu e Lad, respectivamente. 
amoniacal $\left(\mathrm{N}^{-\mathrm{NH}_{4}^{+}}\right)$; alcalinidade parcial (ALCP); nitrogênio nitrito $\left(\mathrm{N}^{-\mathrm{NO}_{2}-}\right)$ e nitrogênio nitrato $\left(\mathrm{N}^{-\mathrm{NO}_{3}}{ }^{-}\right)$; e sólidos suspensos voláteis (SSV). A DQO particulada (DQOP) foi calculada pela diferença da DQO total (DQOT) com a DQO filtrada (DQOF), esta determinada utilizando-se uma membrana de 1,2 $\mu \mathrm{m}$. Nitrogênio total (N-NT) se refere à soma de todas as formas de nitrogênio.

As medições in situ de OD, potencial hidrogeniônico (pH) e temperatura (TEMP) foram realizadas por um medidor multiparâmetro (HACH, modelo 40D).

\section{Extração de DNA e PCR de amostras de lodo}

Para a identificação dos micro-organismos envolvidos, foram coletadas amostras de lodo suspenso e aderido dos dois reatores híbridos, nos seguintes pontos (Figura 1):

- Lsu-1 do compartimento UASB;

- Lsu-2 do compartimento LA;

- Lad-1 do FAN;

- Lad-2 do BAS;

- P3 e P5, referentes também aos pontos de coleta dos efluentes do RHAN e do RHAE, respectivamente. As coletas foram realizadas no final das fases FI (110 dias) e FII (204 dias) em todos os pontos mencionados. As amostras foram nomeadas de acordo com os pontos de coleta pelos quais foram obtidas.

Para o lodo suspenso, foram coletados $300 \mathrm{~mL}$ de amostra em cada ponto (Lsu-1 e Lsu-2). As amostras de lodo aderido (Lad-1 e Lad-2) foram obtidas a partir de oito peças de conduítes. Os conduítes foram congelados $\left(-8^{\circ} \mathrm{C}\right)$, para facilitar a remoção da biomassa aderida, que foi feita por raspagem. Todas as amostras foram centrifugadas ( $3.000 \mathrm{rpm}, 5 \mathrm{~min}, 24^{\circ} \mathrm{C}$ ), lavadas com tampão fosfato salino para remoção de impurezas e novamente centrifugadas. Devido à baixa quantidade de biomassa nos pontos $\mathrm{P} 3$ e $\mathrm{P} 5$, após procedimento de centrifugação e lavagem, uma etapa de filtração foi realizada. Para isso, foi adicionada água ultrapura com resistividade $18,2 \mathrm{M} \Omega$.cm e condutividade < $1 \mu \mathrm{S} . \mathrm{cm}^{-1}$ a $25^{\circ} \mathrm{C}$ para homogeneizar, obtida em aparelho Milli-Q Reference (Merck-Millipore, Brasil). Em seguida, as amostras foram filtradas em membrana de 0,22 $\mu \mathrm{m}$ (Schleicher e Schuell: SeS, Alemanha). Para extração de DNA das amostras P3 e P5, as membranas contendo as biomassas retidas foram cortadas em pequenos pedaços.

Aproximadamente $0,4 \mathrm{~g}$ de cada amostra foi utilizado para extração de DNA, com o kit comercial PowerSoil ${ }^{\mathrm{TM}}$ DNA Isolation Kit (Mobio Laboratories, Califórnia, EUA). A concentração do DNA total foi determinada por espectrofotometria (relação 260/280 nm) utilizando o espectrofotômetro NanoDrop 2000 (Thermo Fisher Scientific, EUA). Os extratos de DNA genômico foram submetidos à amplificação pela técnica da reação em cadeia da polimerase (PCR) utilizando diferentes iniciadores (primers):
- para bactérias desnitrificantes, nirS 2F-nirS 3R (SHOJI et al., 2006);

- BOA, 190F - 1225R (HIKUMA et al., 2002);

- Nitrospira (bactérias oxidantes de nitrito - BON), 232F-1200R (LIM et al., 2008);

- arqueia, 1100F - 1400R (KUDO et al., 1997);

- anammox, AMX 368F - AMX 820R (SCHMIDT; VAN SPANNING; JETTEN, 2004).

\section{RESULTADOS E DISCUSSÃO}

\section{Desempenho do sistema de tratamento}

Os valores médios das análises de amostras dos pontos de coleta P $1_{\text {af }}$ a P5 (Figura 1) do sistema de tratamento, durante as duas fases do período experimental de 204 dias, estão apresentados na Tabela 2. O afluente pode ser classificado como diluído e está coerente com resultados similares reportados previamente para a mesma ETE (KATO; FLORENCIO; ARANTES, 2003; BONFIM et al., 2016; SILVA et al., 2017).

O desempenho do sistema em termos de DQO, sólidos e nitrogênio ao longo da operação está apresentado na Figura 2. A eficiência de remoção de matéria orgânica (Figura 2A) foi próxima a 91\% durante as fases FI e FII, resultando em concentração final de DQO total do sistema (P5) de 33,0 \pm 8,0 mg.L $\mathrm{L}^{-1}$ (FI) e 39,6 \pm 8,0 mg.L-1 (FII) (Tabela 2). Para os sólidos suspensos (Figura 2B), as eficiências foram acima de $95 \%$ em ambas as fases. $\mathrm{O}$ aumento da velocidade ascensional, de 1,21 m.h. ${ }^{-1}$ em FI para 1,41 $\mathrm{m} \cdot \mathrm{h}^{-1} \mathrm{em}$ FII, não resultou em arraste significativo de sólidos no efluente do sistema. E, para ambas as fases, as diferenças entre as concentrações de sólidos no efluente do FAN e do BAS foram inferiores a 4,7 e 3,2 mg.L-1 (Tabela 2), respectivamente.

A formação de um biofilme denso foi observada na superfície do material suporte, tanto no FAN como no BAS. A maior remoção de DQO ocorreu no RHAN, com eficiências de 61,7\% (FI) e 48,6\% (FII), considerando-se as cargas de entrada e saída desse reator. Nessas condições, o RHAE alimentado com o efluente do RHAN apresentou condições favoráveis ao processo de nitrificação, por operar com baixa relação DQO/N (3,3 e 3,9 para FI e FII, respectivamente).

A carga nitrogenada afluente era composta principalmente por nitrogênio amoniacal (78\%); de qualquer forma, observou-se que no RHAN o processo de amonificação foi completo nas duas fases, com todo o nitrogênio orgânico convertido para amoniacal $\left(\mathrm{N}-\mathrm{NH}_{4}^{+}\right)$, confirmado pelos valores iguais de $\mathrm{N}-\mathrm{NH}_{4}^{+}$ e N-NTK no ponto P3 (Tabela 2). Em ambas as fases, uma pequena parcela de nitrato e nitrito recirculado ( $\sim 3 \mathrm{mg} \mathrm{N}-\mathrm{NO}_{3}^{-} \cdot \mathrm{L}^{-1}$ e $0,2 \mathrm{mg} \mathrm{N}-\mathrm{NO}_{2}^{-} \cdot \mathrm{L}^{-1}$, Tabela 2$)$ do RHAE para o RHAN foi desnitrificada. Isso justifica os valores próximos a zero de nitrato e nitrito na saída do RHAN (Figura 2D, Tabela 2).

Tabela 1 - Condições operacionais aplicadas no sistema de tratamento com reatores híbridos de lodo suspenso e aderido durante o período experimental.

\begin{tabular}{|c|c|c|c|c|c|c|c|}
\hline \multirow{2}{*}{ Fases } & \multirow{2}{*}{$\begin{array}{c}\text { Tempo operacional } \\
\text { (d) }\end{array}$} & \multirow{2}{*}{$\begin{array}{l}\text { TDH total } \\
\text { (h) }\end{array}$} & \multicolumn{2}{|c|}{ Recirculação (RR) } & \multirow{2}{*}{$\underset{\left(m \cdot h^{-1}\right)}{V_{\text {asc }}}$} & \multirow{2}{*}{$\begin{array}{c}\mathrm{CO} \\
\left(\mathrm{g} \mathrm{DQO} \cdot \mathrm{d}^{-1}\right)\end{array}$} & \multirow{2}{*}{$\begin{array}{c}\mathrm{CN} \\
\left(\mathrm{g} \mathrm{N} \cdot \mathrm{d}^{-1}\right)\end{array}$} \\
\hline & & & $\left(L . h^{-1}\right)$ & (\%) & & & \\
\hline $\mathrm{FI}$ & 94 & 16 & 28,50 & 50 & 1,21 & 523,9 & 40,5 \\
\hline FII & 110 & 16 & 42,75 & 75 & 1,41 & 552,6 & 41,7 \\
\hline
\end{tabular}

$\mathrm{V}_{\text {acs: }}$ velocidade ascensional. CO: carga orgânica diária. CN: carga nitrogenada diária. RR (\%): em relação à vazão afluente (57 L.h¹).

Fonte: primária. 
Temperatura próxima a $30^{\circ} \mathrm{C}$, $\mathrm{pH}$ entre 6 e 8 e relação DQO/N de 5 são condições favoráveis à remoção simultânea de carbono e nitrogênio em reatores anaeróbios (LU; CHANDRAN; STENSEL, 2014). No presente estudo, as condições de temperatura $\left(30^{\circ} \mathrm{C}\right)$ e $\mathrm{pH}(7,1$ a 7,5$)$ favoreceram a atividade das desnitrificantes, oxidando a matéria orgânica e nitrogênio amoniacal e reduzindo nitrogênio nitrato e nitrito a $\mathrm{N}_{2}$. Além disso, a faixa de $\mathrm{pH}$ aplicada também contribuiu para a estabilidade no RHAN, com tamponamento adequado devido à presença de alcalinidade, com concentrações médias de 210 a $235 \mathrm{mg} \mathrm{CaCO}_{3} \cdot \mathrm{L}^{-1}$ (Tabela 2).

Apesar de a relação DQO/N ter sido maior do que 5 na câmara UASB, os resultados indicam que não houve interferência no processo de desnitrificação no RHAN. Resultados semelhantes foram observados por Xia et al. (2010), que encontraram correlação positiva entre a diversidade microbiana e a relação $\mathrm{DQO} / \mathrm{N}$ de 3 a 10. Bons resultados também foram obtidos com relação à remoção de matéria orgânica no processo de desnitrificação, com relações DQO/N próximas a 10 (XIA et al., 2010; LU; CHANDRAN; STENSEL, 2014; BUENO et al., 2018; DAMIANOVIC et al., 2018).

O processo de nitrificação no sistema de tratamento foi mais intenso no RHAE, conforme esperado. Os resultados no efluente (P5) mostraram significativo consumo de $\mathrm{N}-\mathrm{NH}_{4}{ }^{+}$, coerente com valores de $\mathrm{N}_{-} \mathrm{NO}_{2}{ }^{-}$e
$\mathrm{N}-\mathrm{NO}_{3}$ - produzidos e consumos de alcalinidade para nitrificação (Tabela 2).

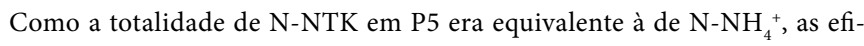
ciências de remoção de N-NTK no sistema foram de 73\% (FI) e 77\% (FII). Ao analisar a eficiência de nitrogênio total (N-NT), os valores obtidos foram próximos a 28 e $50 \%$ nas fases FI e FII, respectivamente. A maior recirculação em FII (RR de 75\%) indicou melhor nitrificação e desnitrificação, que contribuiu para a remoção de nitrogênio.

Adicionalmente, durante a nitrificação no RHAE houve consumo de alcalinidade para oxidação da amônia. Do ponto P3 (efluente do FAN) ao P5 (efluente do BAS), o consumo de alcalinidade foi de 157,2 e 136,0 $\mathrm{mg} \mathrm{CaCO}_{3} \mathrm{~L}^{-1}$ nas fases FI e FII, respectivamente. Consequentemente, a concentração de amônia diminuiu 72,5\% (FI) e 76,8\% (FII), considerando-se os mesmos pontos (P3 e P5). Isso correspondeu a um consumo 7,4 e 5,9 $\mathrm{g} \mathrm{CaCO}_{3} \cdot \mathrm{g}\left(\mathrm{N}_{-} \mathrm{NH}_{4}^{+}\right)^{-1}$, próximo ao valor de 7,05 $\mathrm{g} \mathrm{CaCO}_{3} \cdot \mathrm{g}\left(\mathrm{N}_{-} \mathrm{NH}_{4}^{+}\right)^{-1}$ citado por Rittmann e McCarty (2001). Entretanto, no presente trabalho não ocorreram mudanças significativas de $\mathrm{pH}$ no LA e no BAS, mantendo-se entre 6,9 e 7,2 (Tabela 2).

$\mathrm{O}$ aumento da recirculação e, consequentemente, da velocidade ascensional em FII foi favorável para a redução da concentração média do nitrato no efluente final (P5) para 7,1 $\pm 0,9$ mg. $L^{-1}$ (Tabela 2). Isso pode estar associado à

Tabela 2 - Valores médios das análises físico-químicas nas fases Fl e Fll durante o período experimental (204 dias) para as amostras nos pontos de coleta P1 ${ }_{\text {af }}$ (afluente) e P2 a P5 (efluente dos reatores) dos reatores híbridos.

\begin{tabular}{|c|c|c|c|c|c|c|}
\hline \multicolumn{7}{|c|}{ Fase FI (RR = 50\%) } \\
\hline Parâmetros & $\left(\mathrm{P} 1_{\mathrm{af}}\right)$ & $\left(\mathrm{P} 1_{\mathrm{af}}+\mathrm{P} 1_{\mathrm{rec}}\right)$ & $\begin{array}{l}\text { UASB }_{\text {ef }} \\
\text { (P2) }\end{array}$ & $\begin{array}{l}\mathrm{FAN}_{\mathrm{ef}} \\
\text { (P3) }\end{array}$ & $\begin{array}{l}\mathrm{LA}_{\mathrm{ef}} \\
(\mathrm{P} 4)\end{array}$ & $\begin{array}{l}\mathrm{BAS}_{\mathrm{ef}} \\
\text { (P5) }\end{array}$ \\
\hline $\mathrm{pH}$ & $7,3 \pm 0,1$ & $7,1 \pm 0,1$ & $7,3 \pm 0,1$ & $7,5 \pm 0,1$ & $7,0 \pm 0,1$ & $6,9 \pm 0,2$ \\
\hline $\mathrm{T}\left({ }^{\circ} \mathrm{C}\right)$ & $27,6 \pm 0,4$ & $28,4 \pm 0,4$ & $29,2 \pm 1,2$ & $29,9 \pm 1,1$ & $29,6 \pm 1,5$ & $29,9 \pm 1,1$ \\
\hline $\mathrm{OD}\left(\mathrm{mg} \mathrm{O}_{2} \mathrm{~L}^{\mathrm{L}}\right)$ & $0,2 \pm 0,1$ & $0,8 \pm 0,1$ & $0,5 \pm 0,1$ & $0,3 \pm 0,1$ & $1,6 \pm 0,2$ & $2,1 \pm 0,1$ \\
\hline DQOT (mg O $\left.{ }_{2} \mathrm{~L}^{-1}\right)$ & $383,0 \pm 38,7$ & $266,3 \pm 26,9$ & $137 \pm 10,2$ & $97,6 \pm 10,2$ & $63,9 \pm 14,7$ & $33,0 \pm 8,0$ \\
\hline DQOF $\left(\mathrm{mg} \mathrm{O}_{2} \mathrm{~L}^{-1}\right)$ & $167,3 \pm 23,2$ & $115,1 \pm 16,7$ & $57,8 \pm 11,4$ & $40,4 \pm 9,4$ & $18,2 \pm 4,7$ & $10,9 \pm 4,8$ \\
\hline $\mathrm{DQOP}\left(\mathrm{mg} \mathrm{O}_{2} \mathrm{~L}^{\mathrm{L}} \mathrm{L}^{-1}\right)$ & $215,7 \pm 44,8$ & $151,2 \pm 30,7$ & $79,2 \pm 9,4$ & $57,2 \pm 4,6$ & $45,7 \pm 11,7$ & $22,1 \pm 5,6$ \\
\hline $\mathrm{ALCP}\left(\mathrm{mg} \mathrm{CaCO} \mathrm{C}_{3} \mathrm{~L}^{-1}\right)$ & $229,6 \pm 38,6$ & $179,0 \pm 32,7$ & $232,2 \pm 38,5$ & $235,2 \pm 29,6$ & $142,4 \pm 29,9$ & $78,0 \pm 24,7$ \\
\hline N-NTK (mg.L-1) & $29,6 \pm 1,2$ & $22,4 \pm 1,1$ & $29,6 \pm 1,2$ & $29,1 \pm 1,3$ & $13,6 \pm 2,6$ & $8,0 \pm 1,6$ \\
\hline $\mathrm{N}-\mathrm{NH}_{4}^{+}\left(\mathrm{mg} \cdot \mathrm{L}^{-1}\right)$ & $23,1 \pm 2,1$ & $18,1 \pm 1,7$ & $29,6 \pm 1,2$ & $29,1 \pm 1,3$ & $13,6 \pm 2,6$ & $8,0 \pm 1,6$ \\
\hline $\mathrm{N}-\mathrm{NO}_{2} \cdot\left(\mathrm{mg} \cdot \mathrm{L}^{-1}\right)$ & ND & $0,6 \pm 0,1$ & $0,0 \pm 0,0$ & $0,2 \pm 0,2$ & $1,4 \pm 0,3$ & $1,8 \pm 0,3$ \\
\hline $\mathrm{N}-\mathrm{NO}_{3} \cdot\left(\mathrm{mg} \cdot \mathrm{L}^{-1}\right)$ & ND & $3,9 \pm 0,5$ & $0,0 \pm 0,0$ & $0,2 \pm 0,2$ & $9,0 \pm 1,7$ & $11,6 \pm 1,5$ \\
\hline $\mathrm{SSV}\left(\mathrm{mg} \cdot \mathrm{L}^{-1}\right)$ & $223,0 \pm 12,3$ & $151,8 \pm 7,9$ & $60,9 \pm 18,9$ & $14,4 \pm 2,3$ & $33,2 \pm 10,9$ & $9,4 \pm 4,6$ \\
\hline \multicolumn{7}{|c|}{ Fase FII (RR = 75\%) } \\
\hline Parâmetros & $\left(P 1_{\text {af }}\right)$ & $\left(\mathrm{P} 1_{\mathrm{af}}+\mathrm{P} 1_{\mathrm{rec}}\right)$ & $\begin{array}{l}\text { UASB }_{\text {ef }} \\
(\text { P2) }\end{array}$ & $\begin{array}{l}\text { FAN }_{\text {ef }} \\
(\text { P3) }\end{array}$ & $\begin{array}{l}\mathrm{LA}_{\mathrm{ef}} \\
(\mathrm{P} 4)\end{array}$ & $\begin{array}{l}\mathrm{BAS}_{\mathrm{ef}} \\
\text { (P5) }\end{array}$ \\
\hline $\mathrm{pH}$ & $7,2 \pm 0,1$ & $7,2 \pm 0,1$ & $7,4 \pm 0,1$ & $7,4 \pm 0,1$ & $7,2 \pm 0,1$ & $7,2 \pm 0,1$ \\
\hline $\mathrm{T}\left({ }^{\circ} \mathrm{C}\right)$ & $27,5 \pm 0,5$ & $28,0 \pm 0,3$ & $28,4 \pm 0,4$ & $28,6 \pm 0,5$ & $28,6 \pm 0,5$ & $28,7 \pm 0,5$ \\
\hline $\mathrm{OD}\left(\mathrm{mg} \mathrm{O}_{2} \mathrm{~L}^{-1}\right)$ & $0,2 \pm 0,1$ & $0,3 \pm 0,1$ & $0,4 \pm 0,1$ & $0,4 \pm 0,1$ & $1,7 \pm 0,2$ & $2,3 \pm 0,3$ \\
\hline DQOT (mg O $\left.{ }_{2} \mathrm{~L}^{-1}\right)$ & $404,0 \pm 22,0$ & $247,8 \pm 12,7$ & $158,5 \pm 16,2$ & $118,5 \pm 25,3$ & $69,9 \pm 15,3$ & $39,6 \pm 8,0$ \\
\hline DQOF $\left(\mathrm{mg} \mathrm{O}_{2} \mathrm{~L}^{-1}\right)$ & $176,4 \pm 31,2$ & $105,5 \pm 18,2$ & $65,2 \pm 12,4$ & $44,8 \pm 12,5$ & $26,9 \pm 3,9$ & $11,1 \pm 2,5$ \\
\hline $\mathrm{DQOP}\left(\mathrm{mg} \mathrm{O}_{2} \mathrm{~L}^{-1}\right)$ & $227,6 \pm 40,1$ & $142,3 \pm 21,7$ & $93,3 \pm 11,5$ & $73,7 \pm 20,8$ & $43,0 \pm 13,9$ & $28,5 \pm 7,7$ \\
\hline $\mathrm{ALCP}\left(\mathrm{mg} \mathrm{CaCO} \mathrm{L}_{3} \mathrm{~L}^{-1}\right)$ & $217,4 \pm 14,2$ & $165,4 \pm 9,1$ & $210,1 \pm 17,7$ & $232,1 \pm 19,5$ & $138,4 \pm 28,6$ & $96,1 \pm 7,1$ \\
\hline $\mathrm{N}-\mathrm{NTK}\left(\mathrm{mg} \cdot \mathrm{L}^{-1}\right)$ & $30,5 \pm 1,6$ & $20,4 \pm 1,5$ & $30,4 \pm 1,7$ & $30,2 \pm 1,2$ & $12,5 \pm 3,3$ & $7,0 \pm 2,0$ \\
\hline $\mathrm{N}-\mathrm{NH}_{4}^{+}\left(\mathrm{mg} \cdot \mathrm{L}^{-1}\right)$ & $23,3 \pm 1,0$ & $16,3 \pm 1,2$ & $30,2 \pm 1,2$ & $30,2 \pm 1,2$ & $12,5 \pm 3,3$ & $7,0 \pm 2,0$ \\
\hline $\mathrm{N}-\mathrm{NO}_{2}\left(\mathrm{mg} \cdot \mathrm{L}^{-1}\right)$ & ND & $0,4 \pm 0,2$ & $0,1 \pm 0,1$ & $0,2 \pm 0,2$ & $1,2 \pm 0,3$ & $1,0 \pm 0,4$ \\
\hline $\mathrm{N}-\mathrm{NO}_{3} \cdot\left(\mathrm{mg} \cdot \mathrm{L}^{-1}\right)$ & ND & $3,0 \pm 0,4$ & $0,1 \pm 0,0$ & $0,1 \pm 0,1$ & $5,2 \pm 1,7$ & $7,1 \pm 0,9$ \\
\hline $\mathrm{SSV}\left(\mathrm{mg} \cdot \mathrm{L}^{-1}\right)$ & $305,6 \pm 30,5$ & $180,0 \pm 17,8$ & $64,7 \pm 7,1$ & $19,1 \pm 2,1$ & $32,3 \pm 9,9$ & $12,6 \pm 2,5$ \\
\hline
\end{tabular}

T: temperatura; OD: oxigênio dissolvido; DQOT: demanda química de oxigênio total; DQOF: demanda química de oxigênio filtrada; DQOP: demanda química de oxigênio particulada;

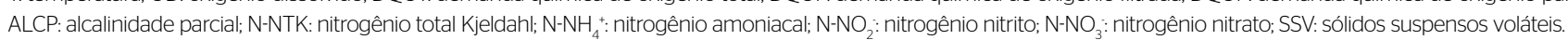
Fonte: primária. 
maior agitação interna nos compartimentos inferiores de cada reator híbrido, promovendo maior contato substrato biomassa (HUANG et al., 2007); além de contribuir para a recuperação instantânea da alcalinidade no RHAN, evitando variações bruscas do $\mathrm{pH}$ e impactos negativos ao processo de nitrificação.

A estabilidade do processo de nitrificação no RHAE também foi influenciada pelo RHAN, com efluente contendo baixa concentração de matéria orgânica e totalmente amonificado (Tabela 2), como mencionado. Assim, a baixa relação DQO/N de 3,3 (FI) e 3,9 (FII) no afluente do RHAE pode ter limitado o desenvolvimento das bactérias heterotróficas, pela baixa disponibilidade de carbono (CALLADO; FORESTI, 2001). Pelo balanço de nitrogênio no RHAE (Figura 3), uma parcela significativa do afluente amonificado não foi convertida em nitrato ou nitrito em FI e FII. Mesmo com baixa remoção de nitrogênio, a presença de bactérias desnitrificantes e oxidantes de amônia e nitrito foi confirmada no RHAE (discutido adiante). Assim, os resultados indicam que o sistema apresenta capacidade de remover matéria orgânica e nitrogênio, mas novos estudos devem ser feitos para melhorar a eficiência de remoção, principalmente de nitrogênio.

A ocorrência de NDS foi demonstrada em estudos anteriores com reatores operando em condições operacionais semelhantes em termos de $\mathrm{pH}(6,7$ a
8,5), temperatura $\left(17\right.$ a $\left.27^{\circ} \mathrm{C}\right)$, relação DQO/N $(1,8$ a 9,7) e OD $(0,1$ a 4,8 mg.L 1) (BUENO et al., 2018; DAMIANOVIC et al., 2018; FENG et al., 2018). Uma recomendação para futuras pesquisas seria o uso de maior recirculação e aeração intermitente; maiores valores de RR poderiam trazer resultados positivos, já que o sistema tem biomassa aderida de forma estável no RHAE e a aeração intermitente foi reportada com bons resultados na remoção de nitrogênio (DAMIANOVIC et al., 2018; FENG et al., 2018).

\section{Comunidade microbiana presente no lodo suspenso e aderido}

A presença de micro-organismos desnitrificantes e nitrificantes, tanto no RHAN como no RHAE, foi confirmada com a PCR das amostras, como mostra a Figura 4. Na fase FI, bactérias desnitrificantes foram identificadas no lodo aderido (Lad1) e no efluente (P3) do FAN; mas não foram identificadas na amostra Lsu-1 da câmara UASB do RHAN, na mesma fase operacional. Na fase FII, tais bactérias estiveram presentes em todos os pontos de coleta do RHAN e do RHAE, como mostra a Figura 4A. A existência de bactérias desnitrificantes, tanto no lodo suspenso quanto no aderido nas duas câmaras (LA e BAS) do RHAE, indica
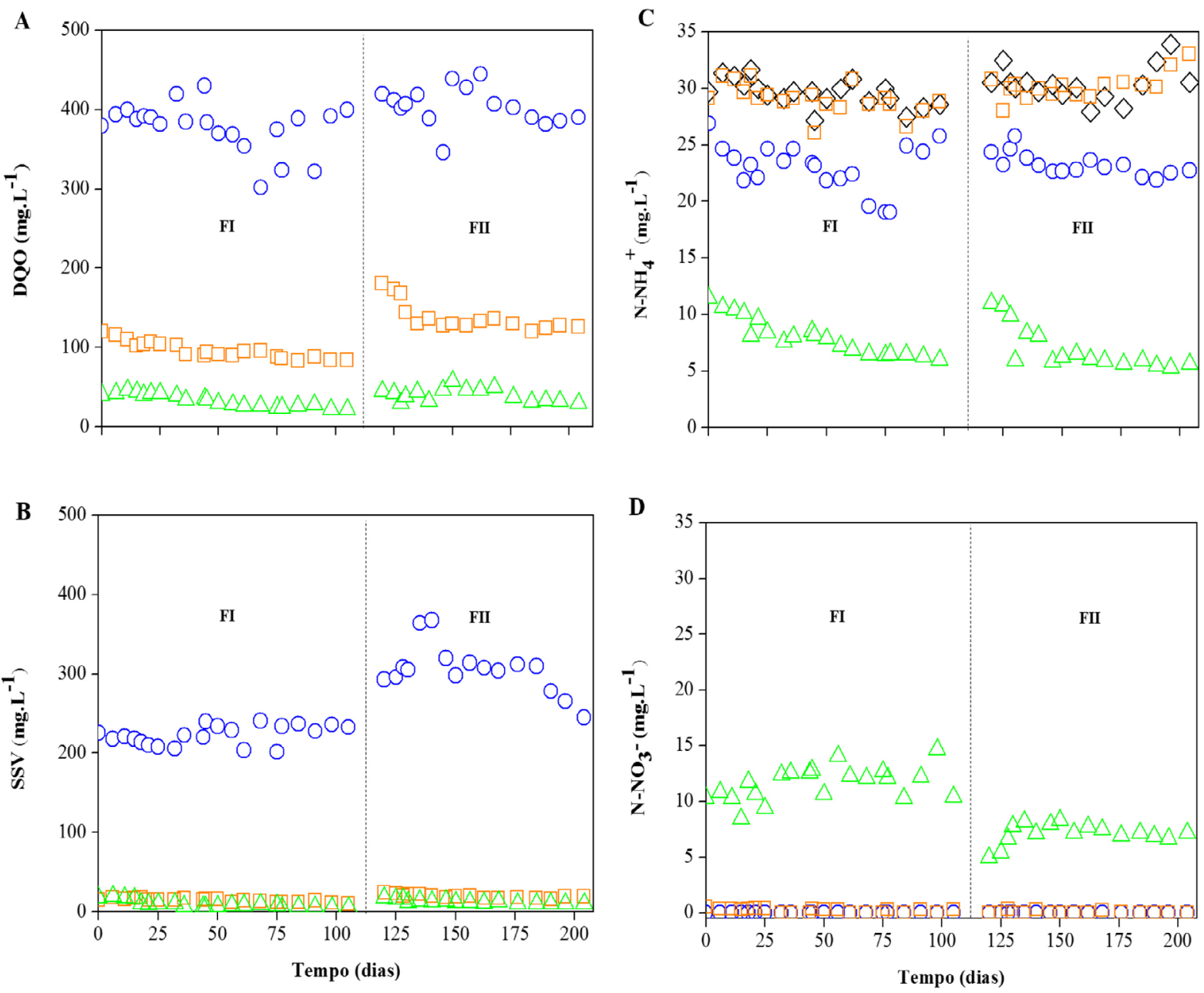

$\mathrm{P1}_{\mathrm{af}}$ afluente do sistema (০); P3: efluente do RHAN ( $\square$ ); P5: efluente final do sistema ( $\triangle$ ); ( $)$ ): N-NTK em Plaf; DQO: demanda química de oxigênio; SSV: sólidos suspensos voláteis. Fonte: primária.

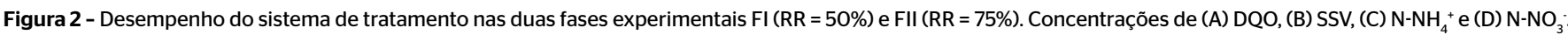


que a biomassa é capaz de realizar o processo de NDS. Relações DQO/N entre 1,8 e 7,6, TDH entre 8 e 10 horas e OD entre 0,1 e 4,8 $\mathrm{mg} \mathrm{O}_{2} \cdot \mathrm{L}^{-1}$ são fatores-chave para a presença de micro-organismos desnitrificantes em reatores aeróbios (BUENO et al., 2018; DAMIANOVIC et al., 2018; FENG et al., 2018); e tais condições são semelhantes às aplicadas ao LA e BAS no presente estudo. Como discutido, a fase FII apresentou melhor remoção de nitrogênio, desempenho que pode estar associado ao processo NDS no RHAE.

Por outro lado, bactérias oxidantes de amônia BOA estiveram presentes em todas as amostras das fases FI e FII (Figura 4B). A operação de reatores com pH 7,2-7,8 e OD 0,5-1,7 mg O ${ }_{2} \cdot \mathrm{L}^{-1}$ favorece maior crescimento dessas bactérias (AHN, 2006; GE et al., 2015) e essas condições são similares às aplicadas no RHAE. O incremento da velocidade ascensional em FII não afetou a presença de BOA no lodo aderido (Lad-1 e Lad-2); a recirculação possivelmente possibilitou a migração dessas bactérias para o RHAN. Além da oxidação da amônia, elas também podem atuar na desnitrificação em condições anaeróbias (SCHMIDT; BOCK, 1997; SCHMIDT; VAN SPANNING; JETTEN, 2004). Isso pode ser associado às menores concentrações de nitrito $\left(0,2 \pm 0,2 \mathrm{mg} \mathrm{N}-\mathrm{NO}_{2} \cdot \mathrm{L}^{-1}\right.$, Tabela 2$)$ no efluente do FAN.

BON foram identificadas na fase FI em amostras efluentes do RHAN (P3) e RHAE (P5), e nas amostras de lodo suspenso (Lsu-1 e Lsu-2) e de lodo aderido, mas nestas apenas no RHAE (Lad-2). Na fase FII, estiveram presentes em todos os pontos de coleta do RHAE, mas no RHAN foram identificadas apenas no lodo aderido (Lad-1) (Figura 4C). Provavelmente, tais bactérias foram lavadas do UASB pelo incremento da recirculação, mas retidas no leito-suporte dos biofilmes do FAN (Lad-1).

Tanto o FAN como o BAS foram eficientes na retenção da biomassa nitrificante, tendo ocorrido a formação de biofilmes densos na superfície do material suporte e evitando a lavagem dos micro-organismos do sistema. Bactérias nitrificantes apresentam taxa de crescimento lento e necessitam de alto TRS para se desenvolver e permanecer no sistema (YU et al., 2010). Alguns autores indicam tempo mínimo de duplicação de 7-8 e 10-13 horas para BOA e BON, respectivamente (PENG; ZHU, 2006). Outros mencionam que TRS de 5 a 30 dias favorecem o crescimento de ambas (LIU; WANG, 2013; YU et al., 2010). Estes últimos autores indicam também que o processo de nitrificação parcial ou convencional depende da concentração de OD adotada, de 0,5-1,7 mg.L $\mathrm{L}^{-1}$ e acima de 2,0 mg. $\mathrm{L}^{-1}$, respectivamente.

Arqueias, identificadas em todas as amostras das fases FI e FII (Figura 4D), são associadas à conversão da matéria orgânica em $\mathrm{CH}_{4}$ e CO $\mathrm{CO}_{2}$ (CADILLO-QUIROZ; YAVITT; ZINDER, 2009). No RHAE, provavelmente, elas se mantiveram ativas nas zonas anaeróbias mais internas do biofilme. Além de atuar na remoção de matéria orgânica, elas podem ter agido na oxidação de amônia. Park et al. (2006) reportaram que algumas arqueias podem oxidar a amônia e contribuir para a remoção de nitrogênio em condições aeróbias; como as suas condições operacionais foram similares, no presente estudo a presença das arqueias oxidantes de amônia (AOA) pode ter sido favorecida. No entanto, para afirmar a principal função dos micro-organismos que compõem a microbiota, mais estudos devem ser realizados.

Micro-organismos capazes de realizar o processo anammox também foram identificados nas amostras do lodo suspenso (Lsu-1) e do ponto de saída (P3) do RHAN em ambas as fases operacionais. No RHAE, eles foram identificados no ponto de saída (P5) e no lodo aderido (Lad), também nas duas fases (Figura $4 \mathrm{E})$. A presença de bactérias com atividade anammox no RHAE pode ter acontecido devido ao seu arraste do RHAN para o RHAE. Zonas anóxicas presentes no RHAE podem ter permitido o desenvolvimento dessas bactérias.
Portanto, os resultados de PCR (Figura 4) indicaram a formação de condições favoráveis para biomassa nitrificante e desnitrificante ativa e estável no sistema durante o período do estudo. Contudo, conforme discutido, novas pesquisas são necessárias para otimizar a remoção de matéria orgânica e nitrogênio.

\section{CONCLUSÕES}

O desempenho do sistema com dois reatores híbridos sequenciais, anaeróbio e aeróbio, cada qual com câmaras de lodo suspenso e aderido, aplicado a esgoto doméstico diluído (DQO $\sim 400 \mathrm{mg} . \mathrm{L}^{-1} \mathrm{e} \mathrm{N}-\mathrm{NT} \sim 30 \mathrm{mg} . \mathrm{L}^{-1}$ ), foi satisfatório na remoção de matéria orgânica carbonácea, mas limitado na remoção de nitrogênio. Para ambos, o melhor desempenho ocorreu na fase II; no efluente final do sistema, a DQO média ficou em $\sim 40 \mathrm{mg} \mathrm{O}_{2} \cdot \mathrm{L}^{-1} \mathrm{e}$ a de nitrogênio total, de 15,1 mg N.L $\mathrm{L}^{-1}$, correspondendo a uma remoção de $91 \%$ e $~ 50 \%$, respectivamente. Tanto a fração do $\mathrm{N}-\mathrm{NH}_{4}{ }_{4}^{+}$como a

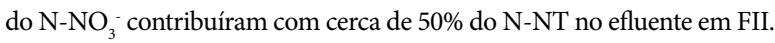

De qualquer maneira, observou-se que a recirculação do efluente aeróbio nitrificado favoreceu o tamponamento do sistema, sem adição de fonte alcalina

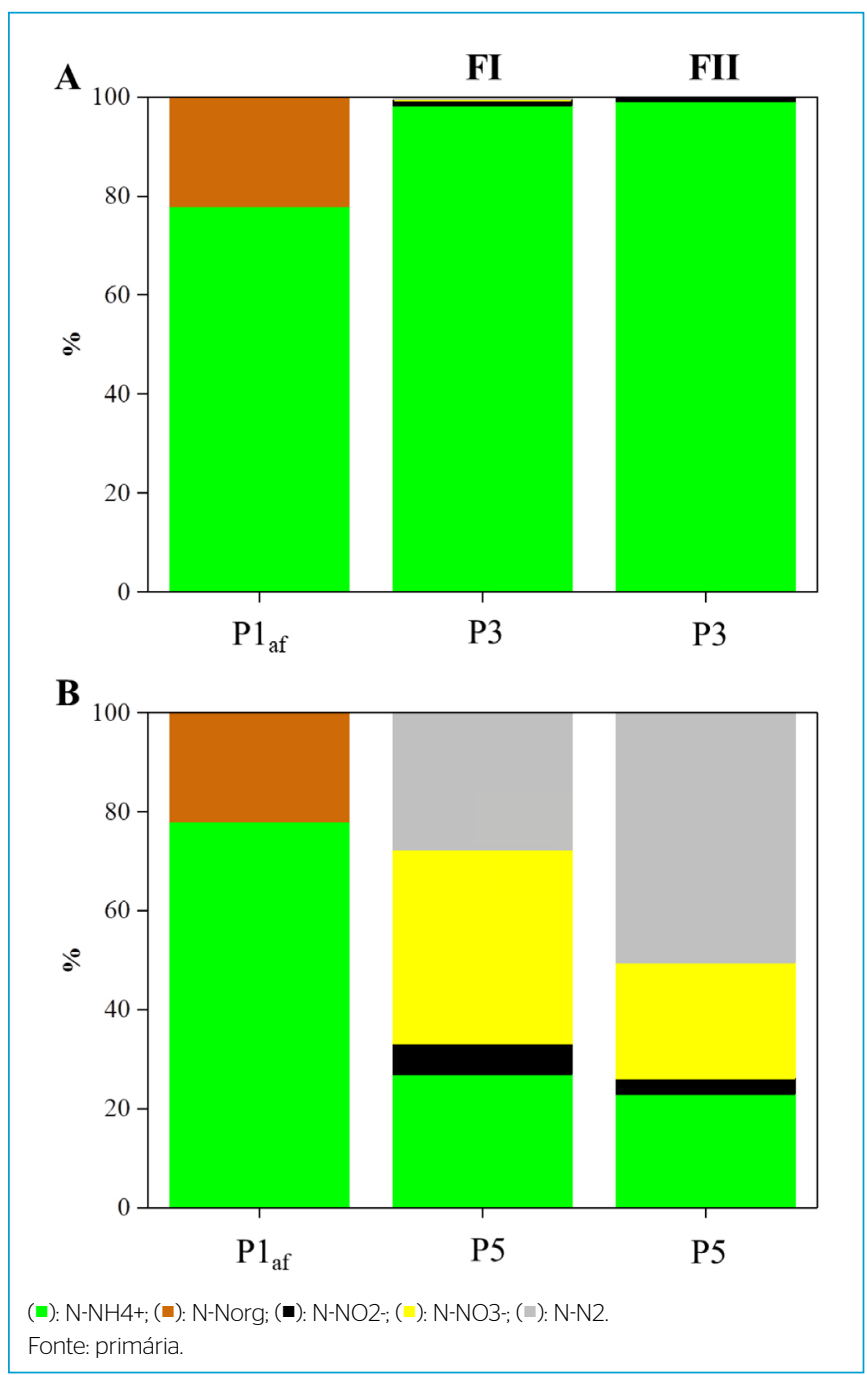

Figura 3 - Balanço de massa de nitrogênio nas fases Fl e Fll dos reatores (A) anaeróbio/RHAN e (B) aeróbio/RHAE, especificando os pontos de coleta de amostra: o afluente ao sistema (P1af), efluente do RHAN (P3) e efluente do RHAE (P5). 
e/ou de doador de elétron externo no processo de desnitrificação no RHAN. A maior razão de recirculação (FII, 75\%) do efluente nitrificado foi favorável à melhor remoção de carbono e nitrogênio, comparada com a da fase FI. A recirculação favoreceu o aumento da biomassa em quantidade e diversidade presente aderida nos meios-suportes. A presença de bactérias desnitrificantes, BOA, BON, arqueias e anammox foi confirmada, indicando condição favorável para o processo NDS. Novas pesquisas são necessárias para otimizar a remoção de matéria orgânica e nitrogênio; uma recomendação seria o uso de maior recirculação e de aeração intermitente.

\section{AGRADECIMENTOS}

Ao Conselho Nacional de Desenvolvimento Científico e Tecnológico (CNPq) è̀ Fundação de Amparo à Ciência e Tecnologia de Pernambuco (FACEPE), o apoio ao projeto PRONEX; à Coordenação de Aperfeiçoamento de Pessoal de Nível Superior (CAPES), a concessão de bolsas de mestrado e doutorado ao LSA-UFPE; à Financiadora de Estudos e Projetos (FINEP), o apoio ao projeto RENTED. Ao INCT ETEs Sustentáveis, os recursos financeiros e as bolsas ao LSA-UFPE. À Companhia de Saneamento de Pernambuco (COMPESA) e à BRK Ambiental, o suporte aos trabalhos experimentais e a coleta de amostras na ETE Mangueira Recife; e à Fibra Revestimentos, a cessão e o suporte na operação de reatores piloto.

\section{CONTRIBUIÇÃO DOS AUTORES}

Santos, M.V.A.: Conceituação, Curadoria de Dados, Análise Formal, Investigação, Metodologia, Escrita - Primeira Redação, Escrita - Revisão e Edição. Morais, J.C.: Conceituação, Curadoria de Dados, Análise Formal, Metodologia, Administração do Projeto, Escrita - Revisão e Edição. Veras, S.T.S.: Conceituação, Curadoria de Dados, Análise Formal, Metodologia, Validação, Visualização, Escrita - Primeira Redação, Escrita - Revisão e Edição. Leite, W.R.M.: Curadoria de Dados, Análise Formal, Investigação, Supervisão, Escrita Primeira Redação. Gavazza, G.: Conceituação, Obtenção de Financiamento, Recursos, Supervisão, Visualização, Escrita - Revisão e Edição. Florencio, L.: Conceituação, Análise Formal, Obtenção de Financiamento, Recursos, Supervisão, Validação, Visualização, Escrita - Revisão e Edição. Kato, M.T.: Conceituação, Análise Formal, Obtenção de Financiamento, Investigação, Metodologia, Administração do Projeto, Recursos, Supervisão, Validação, Visualização, Escrita - Primeira Redação, Escrita - Revisão e Edição.

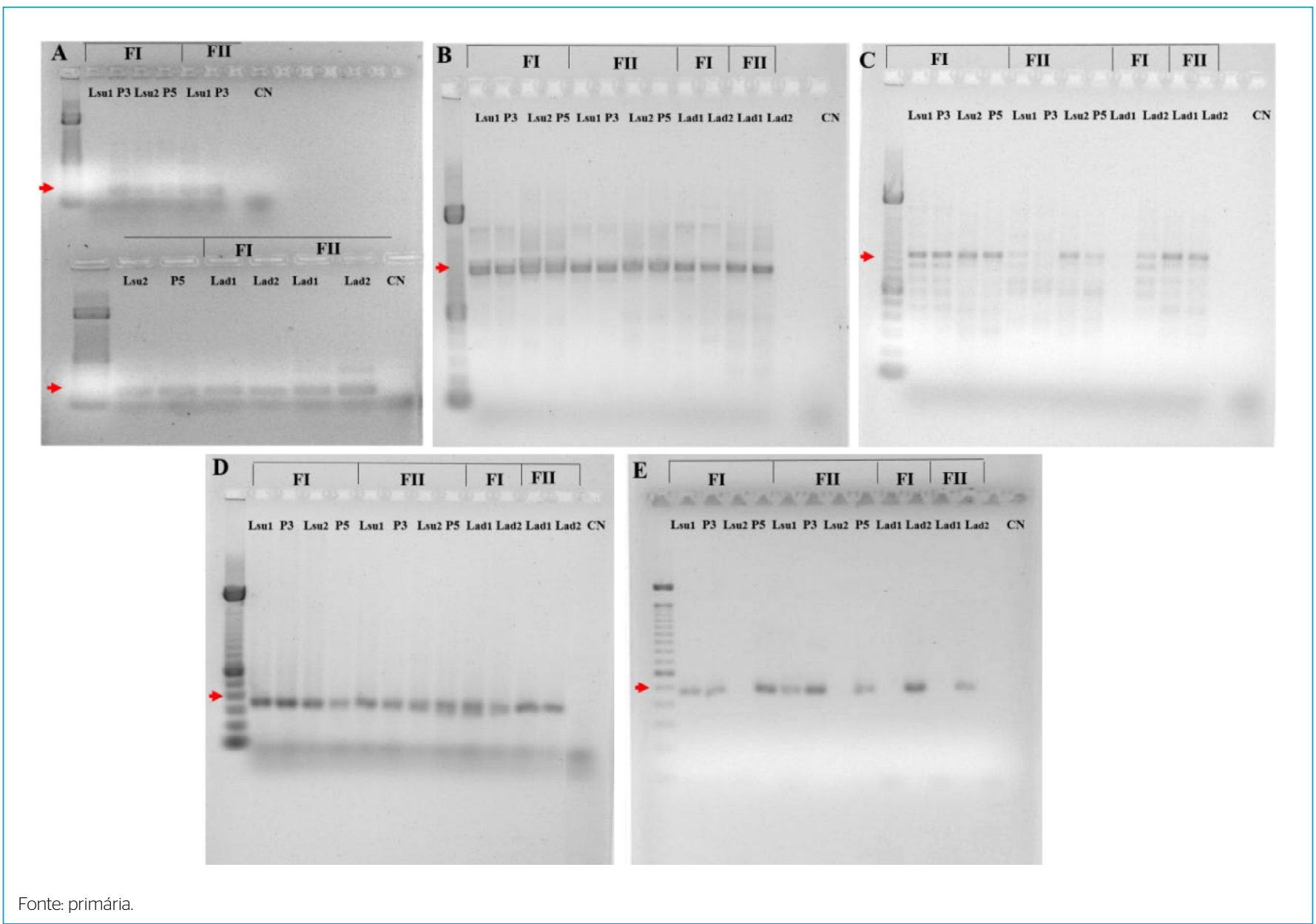

Figura 4 - (A) PCRs para bactérias desnitrificantes, (B) bactérias oxidantes de amônia (BOA), (C) Nitrospira (BOM), (D) arqueias e (E) bactérias com atividade anammox. As amostras das fases FI (RR 50\%) e FII (RR 75\%) estão representadas por: Lsu-1: licor misto do UASB, Lad1: - lodo aderido do FAN, P3 - efluente do FAN, Lsu-2: licor misto do LA, Lad-2: lodo aderido do BAS e P5 - efluente do BAS. Os pares de base (pb), indicados pelas setas vermelhas, estão em (A) $1.000 \mathrm{pb}(190$ Forward (F) - $1225 \mathrm{Reverse}(\mathrm{R})=$ 1.035 pb); (B) 900 pb (232F - 1200R = 968 pb); (C) 100 (2F - 3R =1 pb); (D) 300 pb (1100F - 1400R = 300 pb); (E) 400 pb (AMX $368 F-A M X 820 R=452$ pb). 


\section{REFERÊNCIAS}

AHN, H. Sustainable nitrogen elimination biotechnologies: A review. Process Biochemistry, v. 41, n. 8, p. 1709-1721, 2006. https://doi.org/10.1016/j. procbio.2006.03.033

ALLEGUE, T.; CARBALLO-COSTA, M.N.; FERNANDEZ-GONZALEZ, N.; GARRIDO, J.M. Simultaneous nitrogen and dissolved methane removal from an upflow anaerobic sludge blanket reactor effluent using an integrated fixed-film activated sludge system. Journal of Environmental Management, v. 263, 110395 2020. https://doi.org/10.1016/j. jenvman.2020.110395

AMERICAN PUBLIC HEALTH ASSOCIATION (APHA); AMERICAN WATER WORKS ASSOCIATION (AWWA); WATER POLLUTION CONTROL FEDERATION (WPCF). Standard methods for the examination of water and wastewater. $22^{\text {nd }}$ ed. Washington, D.C.: APHA, 2012.

BARROS, K.K.; GAVAZZA, S.; FLORENCIO, L.; KATO, M.T. The influence of excess sludge discharge on the performance of a full-scale UASB reactor. Water Practice and Technology, v. 10, n. 2, p. 250-258, 2015. https://doi. org/10.2166/wpt.2015.027

BONFIM, J.H.; SILVA, L.G.; GAVAZZA, S.; FLORENCIO, L.; KATO, M.T. Remoção de LAS em esgoto doméstico tratado em reator UASB e lagoa de polimento. Engenharia Sanitária e Ambiental, v. 21, n. 2, p. 397-406, 2016. https://doi.org/10.1590/s1413-41522016123866

BUENO, R.F.; PIVELI R.P.; CAMPOS, F.; ALEM SOBRINHO, P. Simultaneous nitrification and denitrification in the activated sludge systems of continuous flow. Environmental Technology, v. 39, n. 20, p. 2641-2652, 2018. https://doi.org/10.1080/09593330.2017.1363820

CADILLO-QUIROZ, H.; YAVITT, J.B.; ZINDER, H.S. Methanosphaerula palustris gen. nov., sp. nov., a hydrogenotrophic methanogen isolated from a minerotrophic fen peatland. International Journal of Systematic and Evolutionary Microbiology, v. 59, n. 5, p. 928-935, 2009. https://doi. org/10.1099/ijs.0.006890-0

CALLADO, N.H.; FORESTI, E. Removal of organic carbon, nitrogen and phosphorus in sequential batch reactors integrating the aerobic/anaerobic processes. Water Science and Technology, v. 44, n. 4, p. 263-270, 2001. https://doi.org/10.2166/wst.2001.0232

DAMIANOVIC, M.H.R.Z:; SANTOS, C.E.D.; MARTÍN, M.A.M.; FDZ-POLANCO, M.; FORESTI, E.; FDZ-POLANCO, F; GARCIA-ENCINA, A. Specific Activity Bioassays as tools to evaluate combined nitrogen and organic matter removal in SND systems. Environmental Engineering Science, v. 35, n. 9, p. 961-970, 2018. https://doi.org/10.1089/ees.2017.0418

DU, R.; PENG, Y.; JI, J.; SHI, L.; GAO, R. LI, X. Partial denitrification providing nitrite: opportunities of extending application for anammox. Environment International, v. 131, 105001, 2019. https://doi.org/10.1016/j. envint.2019.105001

FENG, L.; JIA, R.; ZENG, Z.; YANG, G.; XU, X. Simultaneous nitrificationdenitrification and microbial community profile in an oxygen-limiting intermittent aeration SBBR with biodegradable carriers. Biodegradation, v. 29, n. 5, p. 473-486, 2018. https://doi.org/10.1007/s10532-018-9845-x

FUCHS, W.; BIERBAUMER, D.; SCHÖPP, T.; WEISSENBACHER, N.; BOUSEK, J. New hybrid reactor concept incorporating a filter mesh for nitritation- anammox treatment of sludge return liquid. Water Science and Technology, v. 76. n. 6, p. 1409-1417, 2017. https://doi.org/10.2166/wst.2017.264

GE, S.J.; WANG, S.; YANG, X.; QIU, S.; LI, B.; PENG, Y. Detection of nitrifiers and evaluation of partial nitrification for wastewater treatment: A review. Chemosphere, v. 140, p. 85-98, 2015. https://doi.org/10.1016/j. chemosphere.2015.02.004

GONZALEZ-TINEO, P.A.; DURÁN-HINOJOSA, U.; DELGADILLO-MIRQUEZ L.R.; MEZA-ESCALANTE, E.R.; GORTÁRES-MOROYOQUI, P.; ULLOAMERCADO, R.G.; SERRANO-PALACIOS, D. Performance improvement of an integrated anaerobic-aerobic hybrid reactor for the treatment of swine wastewater. Journal of Water Process Engineering, v. 34, 101164, 2020. https://doi.org/10.1016/j.jwpe.2020.101164

HIKUMA, M.; NAKAJIMA, M.; HIRAI, T.; MATSUOKA, H. Rapid detection of ammonia oxidizing bacteria in activated sludge based on 16S-rRNA using PCR and fluorometry. Biotechnology Bioprocess Engineering, v. 7. p. 323 326, 2002. https://doi.org/10.1007/BF02932843

HOSSEINPOUR, B.; SABORIMANESH, N.; YERUSHALMI, L.; WALSH, D.; MULLIGAN, C.N. Start-up of oxygen-limited autotrophic partial nitrificationanammox process for treatment of nitrite-free wastewater in a single stage hybrid bioreactor. Environmental Technology, v. 4, p. 1-9, 2019. https://doi.or g/10.1080/09593330.2019.1649467

HU, H.; REN, H. Removal of bioavailable dissolved organic nitrogen in wastewater by membrane bioreactors as posttreatment: implications for eutrophication control. Bioresource Technology, v. 271, p. 496-499, 2019. https://doi.org/10.1016/j.biortech.2018.09.009

HUANG, J.; CHOU, H.; CHEN, C.; CHIANG, C. Effect of recycle to influent ratio on activities of nitrifiers and denitrifies in a combined UASB-activated sludge reactor system. Chemosphere, v. 68, n. 2, p. 382-388, 2007. https:// doi.org/10.1016/j.chemosphere.2007.01.037

KATO, M.T; FLORENCIO, L.; ARANTES, R.F.M. Post-treatment of UASB effluent in an expanded granular sludge bed reactor type using flocculent sludge. Water Science and Technology, v. 48, n. 6, p. 279-284, 2003. https:// doi.org/10.2166/wst.2003.0413

KUDO, Y.; NAKAJIMA, T.; MIYAKI, T.; OYAIZU, H. Methanogen flora of paddy soils in Japan. FEMS Microbiology Ecology, v. 22, n. 1, p. 39-48, 1997. https:// doi.org/10.1111/j.1574-6941.1997.tb00354.x

LETTINGA, G.; DE MAN, A.; VAN DER LAST, A.R.M.; WIEGANT, W.; VAN KNIPPENBERG, K.; FRIJNS, J.; VAN BUUREN, J.C.L. Anaerobic treatment of domestic sewage and wastewater. Water Science and Technology, v. 27, n. 9. p. 67-73, 1993. https://doi.org/10.2166/wst.1993.0179

LEYVA-DIAZ, J.C.; MUÑIOO, M.M.; GONZÁLEZ-LÓPEZ, J:; POYATOS, J.M. Anaerobic/anoxic/oxic configuration in hybrid moving bed biofilm reactor membrane bioreactor for nutrient removal from municipal wastewater Ecological Engineering, v. 91, p. 449-458, 2016. https://doi.org/10.1016/j. ecoleng.2016.03.006

LIM, J.; DO, H.; SHIN, S.G.; HWANG, S. Primer and probe sets for groupspecific quantification of the genera Nitrosomonas and Nitrospira using real-time PCR. Biotechnology and Bioengineering, v. 99, n. 6, p. 1374-1383, 2008. https://doi.org/10.1002/bit.21715 
LIU, G.Q.; WANG, J.M. Long term low DO enrich and shifts nitrifier community in activated sludge. Environmental Science and Technology, v. 47, n. 10, p. 5109-5117, 2013. https://doi.org/10.1021/es304647y

LU, H.; CHANDRAN, K.; STENSEL, D. Microbial ecology of denitrification in biological wastewater treatment. Water Research, v. 64, p. 237-254, 2014. https://doi.org/10.1016/j.watres.2014.06.042

MIAO, Y.; PENG, Y.; XHANG, L.; LI, B.; LI, X.; WU, L.; WANG, S. Partial nitrificationanammox (PNA) treating sewage with intermittent aeration: Effect of influent C/N ratios. Chemical Engineering Journal, v. 334, p. 664-672, 2018. https://doi.org/10.1016/j.cej.2017.10.072

MÜNCH, E.V.; LANT, P.; KELLER, J. Simultaneous nitrification and denitrification in bench-scale sequencing batch reactors. Water Research, v. 30, n. 2, p. 277-284, 1996. https://doi.org/10.1016/0043-1354(95)00174-3

OLIVEIRA NETTO, A.P.; ZAIAT, M. Treatment of domestic sewage in an anaerobic-aerobic fixed-bed reactor with recirculation of the liquid phase. Clean Soil, Air, Water, v. 40, n. 9, p. 965-971, 2012. https://doi.org/10.1002/ clen.201100672

PANTOJA FILHO, J.L.R.; DAMIANOVIC, M.H.R.Z.; FONSECA, D.F.; FORESTI, E. Nitrogen and residual organic matter removal from anaerobic reactor effluent in a fixed bed reactor with biogas for denitrification. Journal of Chemical Technology and Biotechnology, v. 90, n. 12, p. 2227-2233, 2015. https://doi.org/10.1002/jctb.4537

PARK, H.; WELLS, G.F.; BAE, H.; CRIDDLE, C.S.; FRANCIS, C.A. Occurrence of ammonia oxidizing archaea in wastewater treatment plant bioreactors. Applied and Environment Microbiology, v. 72, n. 8, p. 5643-5647, 2006. https://doi.org/10.1128/AEM.00402-06

PATHAK, N.; PHUNTSHO, S.; TRAN, V.H.; JOHIR, M.A.H.; GHAFFOUR, N.; LEIKNES, T.; FUJIOKA, T.; SHON, H.K. Simultaneous nitrificationdenitrification using baffled osmotic membrane bioreactormicrofiltration hybrid system at different oxic-anoxic conditions for wastewater treatment. Journal of Environmental Management, v. 253, 109685, 2020. https://doi.org/10.1016/j.jenvman.2019.109685

PENG, Y.; ZHU, G. Biological nitrogen removal with nitrogen and denitrification via nitrite pathway. Applied Microbiology and Biotechnology, v. 73, n. 1, p. 15-26, 2006. https://doi.org/10.1007/s00253-006-0534-z

PITTMAN, J.K.; DEAN, A.P.; OSUNDEKO, O. The potential of sustainable algal biofuel production using wastewater resources. Bioresource Technology, v. 102, n. 1, p. 17-25, 2011. https://doi.org/10.1016/j.biortech.2010.06.035
RITTMANN, B.E.; MCCARTY, P.L. Environmental biotechnology: principles and applications. Nova York: McGraw Hill, 2001.

SCHMIDT, I.; BOCK, E. Anaerobic ammonia oxidation with nitrogen dioxide by Nitrosomonas eutropha. Archives of Microbiology, v. 167, p. 106-111, 1997. https://doi.org/10.1007/s002030050422

SCHMIDT, I.; VAN SPANNING, R.J.M.; JETTEN, M.S.M. Denitrification and ammonia oxidation by Nitrosomonas europea wild-type, and Nirk-and NorB-deficient mutants. Microbiology, v. 150, n. 12, p. 4107-4114, 2004. https:// doi.org/10.1099/mic.0.27382-0

SHOJI, T.; NITTAMI, T:; ONUKI, M.; SATOH, H.; MINO, T. Microbial community of biological phosphorus removal process fed with municipal wastewater under different electron acceptor conditions. Water Science and Technology, v. 54, n. 1, p. 81-89, 2006. https://doi.org/10.2166/wst.2006.375

SILVA, L.G.; GAVAZZA, S.; FLORENCIO, L.; KATO, M.T. Quantificação de alquilbenzeno linear sulfonato em estação de tratamento de efluentes e rios por cromatografia líquida de alta eficiência e extração em fase sólida. Química Nova (Online), v. 40, n. 3, p. 334-341, 2017. https://doi.org/10.21577/0100-4042.20170007

STEIN, L.Y. Insights into the physiology of ammonia oxidizing microorganisms. Current Opinion in Chemical Biology, v. 49, p. 9-15, 2019. https://doi.org/10.1016/j.cbpa.2018.09.003

WALIA, R.; KUMAR, P.; MEHROTRA, I. Post-treatment of effluent from UASB reactor by surface aerator. International Journal of Environmental Science and Technology, v. 17, p. 983-992, 2020. https://doi.org/10.1007/s13762-019O2351-1

XIA, S.; LI, J.; WANG, R.; LI, J.; ZHANG, Z. Tracking composition and dynamics of nitrification and denitrification microbial community in a biofilm reactor by PCR-DGGE and combining FISH with flow cytometry. Biochemical Engineering Journal, v. 49, n. 3, p. 370-378, 2010. https://doi.org/10.1016/j. bej.2010.01.013

XIA, Z.; WANG, Q.; SHE, Z., GAO, M.; ZHAO, Y.; GUO, L.; JIN, C. Nitrogen removal pathway and dynamics of microbial community with the increase of salinity in simultaneous nitrification and denitrification process. Science of the Total Environment, v. 697, 134047, 2019. https://doi.org/10.1016/j. scitotenv.2019.134047

YU, T.; QI, R.; LI, D:; ZHANG, Y.; YANG M. Nitrifier characteristics in submerged membrane bioreactors under different sludge retention times. Water Research, v. 44, n. 9, p. 2823-2830, 2010. https://doi.org/10.1016/j.watres.2010.02.021 